ISSN 2587-8123 (Print) ISSN 2658-5995 (Online)

МИНИСТЕРСТВО НАУКИ И ВЫСШЕГО ОБРАЗОВАНИЯ РОССИЙСКОЙ ФЕДЕРАЦИИ ВОЛГОГРАДСКИЙ ГОСУДАРСТВЕННЫЙ УНИВЕРСИТЕТ

НИЖНЕВОЛЖСКИЙ АРХЕОЛОГИЧЕСКИЙ ВЕСТНИК 2021 Tом 20. № 2

MINISTRY OF SCIENCE AND HIGHER EDUCATION OF THE RUSSIAN FEDERATION VOLGOGRAD STATE UNIVERSITY

THE LOWER VOLGA ARCHAEOLOGICAL BULLETIN 2021 Volume 20. No. 2

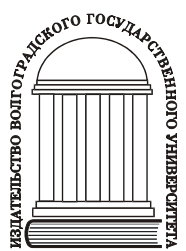




\section{СОДЕРЖАНИЕ}

Конец прекрасной эпохи (Редакциионная коллегия) .... 5

\section{СТАТЬИ}

Файзуллин И.А., Купцова Л.В., Мухаметдинов В.И. Гончарное производство срубной культуры Предуралья по материалам курганного могильника I у села Твердилово

Балабанова М.А., Клепиков В.М., Перерва Е.В. Погребальный обряд и морфология погребенного из кургана могильника Тау (Западный Казахстан) .... 24

Монахов С.Ю. Типология и хронология аканфских амфор [На англ. яз.] 43

Абрамова А.Н. Население Прикубанья раннего железного века по данным краниофенетики (предварительные данные) .66

Малашев В.Ю., Маслов В.Е. Курганы-кладбища центральных и восточных районов Северного Кавказа III в. до н.э. - начала (первой половины) II в. н.э. (памятники типа Чегем-Манаскент)

Ковалева К.С. Производственные

бронзолитейные комплексы

городов Золотой Орды: поиск аналогий

Дрёмов И.И., Круглов Е.В. Железные конусы в погребениях Улуса Джучи:

аспекты этнокультурной принадлежности 149

Гаглойты Р.Х., Кочкаров У.Ю., Мамаев Р.Х., Нарожный В.Е., Нарожный Е.И. Наконечники копий келийского каменноящечного могильника (Горная Ингушетия)

\section{ПУБЛИКАЦИИ}

Кривочеев М.В., Моисеев В.И.

Погребения раннесарматского времени

с территории Чеченской Республики

Иванов С.С. Редкая поясная бляха

в зооморфном стиле с Внутреннего Тянь-Шаня..... 196

Николаев С.Ю. Три сарматских кинжала

с подножия горы Торатау 204

\section{НАУЧНАЯ ЖИЗНЬ}

Итоги VI Нижневолжской Международной археологической научной конференции «Волго-Уральский регион от древности до Средневековья» (Оргкомитет конферениии) 214

\section{CONTENTS}

The End of a Great Era (Editorial Staff) 5

\section{ARTICLES}

Fayzullin I.A., Kuptsova L.V., Mukhametdinov V.I. The Ceramics Production of the Cis-Ural Srubnaya Culture: A Case Study of the Kurgan Cemetery I Near Tverdilovo Village ..... 8

Balabanova M.A., Klepikov V.M., Pererva E.V. Funeral Rite and Morphology of a Buried Man from Kurgan of Tau Cemetery (Western Kazakhstan) .... 24 Monakhov S.Yu. Typology and Chronology of Akanthian Amphorae

Abramova A.N. Craniophenetic Features

of Cis-Kuban Population of the Early Iron Age (Preliminary Data)

Malashev V.Yu., Maslov V.E. Kurgan-Cemeteries of Central and Eastern Regions of North Caucasus $3^{\text {rd }}$ Century BC - Early $2^{\text {nd }}$ Century AD

(Monuments Chegem-Manaskent Type)

Kovaleva K.S. Manufacturing Complexes for the Non-Ferrous Metals Processing of the Golden Horde Cities: Search for Analogies

Dremov I.I., Kruglov E.V. Iron Cones

in the Burials of Ulus Jochi:

Aspects of Ethnocultural Identification

Gagloiti R.H., Kochkarov U.U., Mamaev R.Kh., Narozhnyi V.E., Narozhnyi E.I. Spearheads of the Keliysky Stone Box Burial Ground (Ingushetia Highlands)

\section{PUBLICATIONS}

Krivosheev M.V., Moiseev V.I.

Early Sarmatian Burials

from the Chechen Republic Territory

Ivanov S.S. A Rare Belt Plaque in Zoomorphic Style from the Inner Tien Shan.... 196

Nikolaev S.Yu. Three Sarmatian Daggers

from the Foot of Toratau Mount

\section{SCIENTIFIC LIFE}

Proceedings of the $6^{\text {th }}$ Lower Volga International Scientific Conference on Archaeology

"The Volga-Ural Region -

from Antiquity to the Middle Ages"

(Organizing Committee of the Conference) 214 


\title{
EARLY SARMATIAN BURIALS FROM THE CHECHEN REPUBLIC TERRITORY ${ }^{1}$
}

\author{
Mikhail V. Krivosheev \\ Volgograd State University, Volgograd, Russian Federation \\ Vladimir I. Moiseev \\ Volgograd State University, Volgograd, Russian Federation
}

\begin{abstract}
In 2018, Kurgan 2 of Gvardeyskiye 3 Kurgany (the $3^{\text {rd }}$ Gvardeiskiy Kurgans) in the Nadterechny District of the Chechen Republic was studied. In the result, nine burials were found in the Kurgan which was created during the Early Bronze Age and continued to be used in the course of the Middle and Late Bronze Age. However, the three most recent burials date back to the Early Iron Age period. The burials were localized inside the existing embankment and formed a compact group. In two cases, the burial type was not identified; nevertheless in one case, the burial was constructed in a catacomb. The grave goods are mainly presented by ceramic vessels from the workshops of the sedentary population from the foothill area of Central and Eastern North Caucasus regions. The conclusion was made that the investigated Kurgans were left by the nomadic North Caucasian steppes population of the $3^{\text {rd }}-1^{\text {st }}$ centuries $B C$ due to the feature analysis of the Early Iron Age burial complexes.

Key words: nomads, North Caucasian steppes, North Caucasus, Chechen Republic, burial mound, Gvardeyskiye 3 Kurgany (the $3^{\text {rd }}$ Gvardeiskiy Kurgans), Early Sarmatian period, $3^{\text {rd }}-1^{\text {st }}$ centuries BC.

Citation. Krivosheev M.V., Moiseev V.I., 2021. Pogrebeniya rannesarmatskogo vremeni s territorii Chechenskoy Respubliki [Early Sarmatian Burials from the Chechen Republic Territory]. Nizhnevolzhskiy Arkheologicheskiy Vestnik [The Lower Volga Archaeological Bulletin], vol. 20, no. 2, pp. 186-195. DOI: https://doi.org/10.15688/nav.jvolsu.2021.2.9
\end{abstract}

УДК 930.26(470+571):903.5
Дата поступления статьи: 03.09.2021

Дата принятия статьи: 30.10 .2021

\section{ПОГРЕБЕНИЯ РАННЕСАРМАТСКОГО ВРЕМЕНИ С ТЕРРИТОРИИ ЧЕЧЕНСКОЙ РЕСПУБЛИКИ ${ }^{1}$}

\author{
Михаил Васильевич Кривошеев \\ Волгоградский государственный университет, г. Волгоград, Российская Федерация \\ Владимир Иванович Моисеев \\ Волгоградский государственный университет, г. Волгоград, Российская Федерация
}

Аннотация. В 2018 г. в Надтеречном районе Чеченской Республики был исследован курган 2 могильника «Гвардейские 3-и курганы». В кургане обнаружено 9 погребений. Курган был создан в эпоху ранней бронзы и продолжал использоваться в эпоху средней и поздней бронзы. Три наиболее поздних захоронения 
относятся к эпохе раннего железного века. Погребения были впущены в существовавшую насыпь и образовывали компактную группу. В двух случаях тип могил не определялся, в одном - захоронение совершено в катакомбе. Могильный инвентарь представлен в основном керамическими сосудами из мастерских оседлого населения предгорной полосы центральных и восточных районов Северного Кавказа. Анализ особенностей погребальных комплексов раннего железного века в исследуемом кургане позволяет говорить о том, что они оставлены кочевническим населением северокавказских степей III-I вв. до н.э.

Ключевые слова: кочевники, северокавказские степи, Северный Кавказ, Чеченская Республика, курганный могильник, «Гвардейские 3-и курганы», раннесарматское время, III-I вв. до н.э.

Цитирование. Кривошеев М. В., Моисеев В. И., 2021. Погребения раннесарматского времени с территории Чеченской Республики // Нижневолжский археологический вестник. Т. 20, № 2. C. 186-195. DOI: https://doi.org/10.15688/nav.jvolsu.2021.2.9

В июне - июле 2018 г. в Надтеречном районе Чеченской Республики археологической экспедицией ООО «Научно-производственный центр “ДАРС”» в зоне проектируемого строительства магистрального газопровода Моздок - Грозный под руководством М.В. Кривошеева были проведены аварийно-спасательные раскопки кургана № 2 на курганном могильнике «Гвардейские 3-и курганы».

Могильник располагался на пахотных полях в 3,7 км к юго-востоку от юго-восточной окраины с. Братское и в 4,4 км к югу от с. Гвардейское (рис. 1). Диаметр кургана составлял 47 м, современная высота - 0,7 м.

В процессе раскопок было выявлено, что курган был возведен в эпоху ранней бронзы с применением сложных архитектурных решений и продолжал использоваться в эпоху средней и поздней бронзы [Кривошеев, Клещенко, 2020]. В кургане были обнаружены 9 погребений. Наиболее поздние захоронения в кургане (погр. № 1, 2, 7) были совершены в раннем железном веке. О них и пойдет речь в статье.

В XX в. курган попал в зону сельскохозяйственного освоения и был спланирован до современной высоты. Реконструируемая высота первичной насыпи, созданной в эпоху бронзы, могла превышать 2 м [Кривошеев, Клещенко, 2020, с. 119].

Впускные погребения раннего железного века находились к северо-востоку от центра кургана в непосредственной близости, не нарушая друг друга (рис. 2,1).

Погребение № 1 находилось в насыпи кургана, под пахотным слоем, на расстоянии 8,15 м к ССВ $\left(25^{\circ}\right)$ от ЦР. Форма и размеры могильной ямы не прослеживались. Дно ямы ровное, зафиксировано по уровню залегания скелета. На дне ямы был обнаружен скелет женщины 35-45 лет ${ }^{2}$, уложенный вытянуто на спине, головой на С3. Руки погребенной были согнуты в локтях под прямым углом; правая кисть лежала на животе, левая - на уровне грудины. Ноги вытянуты, сведены в коленях и стопах (рис. 2,2).

На дне ямы, слева от черепа, на расстоянии 0,3 м был обнаружен развал сосуда с ручкой (рис. 2,3) и невысоким, слегка отогнутым наружу венчиком, округлым туловом и слабовогнутым дном. Снаружи венчик оформлен в виде невысокого валика. Петлевидная, подтрапециевидная в сечении ручка крепится к средней части тулова. Плечики маркирует орнаментальный поясок из трех горизонтальных несмыкающихся желобков. Тулово декорировано пучками вертикальных каннелюр (по три линии в каждом пучке). На тулове, а также на фрагменте венчика имеются просверленные отверстия (следы ремонта). Наружная поверхность кувшина темно-серого цвета с коричневатыми пятнами, заглажена, со следами лощения. Глина в изломе серого цвета, с добавками светлого песка. Сосуд сформован на медленном гончарном круге. Обжиг восстановительный. Высота 14,1 см. Диаметр тулова - 18,3 см. Диаметр дна - 9,6 см.

У правого локтя погребенной находился фрагмент небольшого железного однолезвийного ножа с черенком (рис. 2,4). Длина ножа - 4,85 см. Длина черенка - до $1,8 \mathrm{~cm}$.

Под ножом, на дне, лежал кусок мелкозернистого необработанного камня с прямыми гранями, без следов обработки. Размеры: $5,3 \times 4,1 \times 3,7 \mathrm{~cm}$. 
Погребение № 2 зафиксировано в насыпи кургана, под пахотным слоем, на расстоянии 7,6 м к СВ $\left(36^{\circ}\right)$ от ЦР. Форма и размеры могильной ямы не прослеживались. Дно ямы ровное. На дне обнаружен скелет женщины (?) 45-55 лет, уложенный вытянуто на спине, головой на ЮЗ. Череп раздавлен и завален направо. Руки согнуты в локтях. Кисть правой руки располагалась на поясничном отделе позвоночника. Левая рука согнута под острым углом, кисть на лопатке. Кости стоп нарушены землероями, но, видимо, были разведены в стороны (рис. 3,1).

На дне ямы, с правой стороны от погребенной, вдоль правой ноги и до середины правого плеча, а также под костяком зафиксирована прослойка органического тлена темносерого цвета.

В районе левого запястья и на левой стороне груди погребенной обнаружен мелкий бисер плохой сохранности (рис. 3,2). Бисер также зафиксирован в районе поясничного отдела позвоночника и правого запястья. Бисер округлой формы из бесцветного прозрачного (?) стекла (24 шт.).

На позвонках грудного отдела обнаружены фрагменты бронзового, сильно корродированного пластинчатого предмета. Длина 3,4 см, толщина -0,2 см (рис. 3,3 ).

С внешней стороны левого локтевого сустава, на дне погребения, обнаружено бронзовое кольцо из тонкой проволоки в 1,5 оборота (рис. 3,5 ). Изготовлено из круглой в сечении проволоки; один край заостренный. Размеры: $2,5 \times 2,3$ см.

С внешней стороны правого локтевого сустава, на дне, зафиксированы крупные древесные угольки, уложенные в ряд длиной $5 \mathrm{~cm}$, вероятно от одного предмета.

В ногах погребенной, слева на дне, стояла крупная сероглиняная миска с загнутым внутрь бортиком, переходящим в низкий, слегка отогнутый венчик. Дно плоское (рис. 3,6). Стенки украшены орнаментальным пояском из вертикальных линий. Тесто рыхлое (расслаивается), с добавками большого количества песка. Обжиг восстановительный, слабый (фрагменты разрушаются под воздействием воды). Миска сформована на медленном гончарном круге. Высота - около 9,5 см. Диаметр венчика - около 30 см. Диаметр дна - около 8,5 см.
В миске лежали кости молодого барана: 2 части ребер в сочленении и кости передней ноги с лопаткой в сочленении.

Здесь же в миске обнаружен железный однолезвийный нож с горбатой спинкой и черенком (рис. 3,4 ). Длина $-7,4$ см. Ширина клинка максимальная - 1,7 cм.

Рядом с миской стоял крупный фрагментированный сосуд, сформованный на медленном гончарном круге (рис. 3,7 ). Глина в изломе светло-коричневого цвета с добавками песка. Обжиг восстановительный. Высота сохранившаяся - 17,3 см. Диаметр дна 12 см, диаметр тулова - 21,2 см.

В районе стоп на дне ямы обнаружен кусок мелкозернистого рыхлого песчаника бледно-желтого цвета, неправильной формы, без следов обработки. Размеры: $6,1 \times 5 \times 2,7$ см.

Погребение № 7 обнаружено в северо-восточном секторе кургана на расстоянии 8,35 м к $\mathrm{CB}\left(45^{\circ}\right)$ от ЦР. Погребение совершено в катакомбе, ориентированной длинной осью по линии ВСВ - ЗЮЗ. Входная яма и камера расположены по одной оси. Входная яма была расположена в ВСВ части камеры и, вероятно, представляла собой вертикальную шахту шириной $0,8 \mathrm{M}$, длиной до 0,5 м, глубиной -1,58 м. Дно входной ямы ровное.

В ЗЮЗ стенке входной ямы находился вход в прямоугольную камеру. Дно входной ямы плавно переходит в дно камеры и понижается к ЗЮЗ стенке до глубины -1,82 м.

Длина входной ямы - 0,5, длина камеры - 1,64 м, ширина - 0,8 м. Реконструируемая высота свода в средней части камеры могла достигать $0,56 \mathrm{~m}$.

На дне камеры по центральной оси вытянуто на спине лежал скелет женщины старше 55 лет, головой к ЗЮЗ. Руки согнуты в локтях; левая кисть - на груди, правая - на поясе. Ноги вытянуты (рис. 3,8).

В районе шейных и грудных позвонков обнаружены 4 бусины (рис. 3,9):

a) эллипсоидная бусина из оранжевого прозрачного сердолика;

б) фигурная подвеска из черного гагата с уплощенной петелькой и округлой нижней частью;

в) округлая бусина из бесцветного прозрачного стекла; 
г) небольшая эллипсоидная бусина из темно-серого, почти черного стекла.

На правом запястье обнаружен мелкий бисер (8 шт.) (рис. 3,10$)$ :

a) эллипсоидной формы из черного гагата (6 шт.);

б) цилиндрической формы из черного гагата;

в) эллипсоидной формы из светло-коричневого полупрозрачного стекла.

На левом запястье обнаружен мелкий бисер (8 шт.) (рис. 3,11):

a) эллипсоидной (5 шт.) и цилиндрической (2 шт.) формы из черного гагата;

б) округлой формы из синего полупрозрачного стекла.

На дне входной ямы у северной стенки стоял сероглиняный кувшин без выделенного венчика, с прогнутым в средней части горлом, шарообразным туловом и слабовогнутым дном (рис. 3,13). Плечики маркирует поясок из трех несмыкающихся узких желобков. Тулово декорировано пучками вертикальных каннелюр (по три линии в каждом пучке). Ручка находится на плечиках и крепится верхним прилепом с помощью штифта через отверстие в стенке (изнутри замазано). Наружная поверхность черного цвета с коричневыми пятнами, заглажена, со следами лощения. Глина в изломе коричневого цвета, с добавками песка. Сосуд сформован на медленном гончарном круге. Обжиг восстановительный. Высота - 21 см. Диаметр венчика - около 10 см. Диаметр горла - 9,1 см. Диаметр тулова - 19,7 см. Диаметр дна - 11 см.

В районе голеней погребенного обнаружены бусы (17 шт.) (рис. 3,12):

a) небольшие эллипсоидной формы из черного гагата (2 шт. и 1 фрагмент);

б) эллипсоидной формы из светло-коричневого полупрозрачного стекла (1 шт.);

в) округлой формы из зеленого полупрозрачного стекла (1 шт.);

г) округлой и неправильной цилиндрической формы небольшие бусы из синего полупрозрачного стекла (4 шт.);

д) небольшие округлой формы из синезеленого полупрозрачного стекла (4 шт.);

е) небольшие округлой формы из черного (?) непрозрачного (?) стекла (4 шт.).
По всей площади дна камеры катакомбы, в том числе под костяком, зафиксирована подстилка органического тлена (кора).

Под костями черепа, грудной клетки, таза и коленями, под слоем древесного тлена обнаружен слой белесого тлена.

Планиграфия кургана № 2 курганного могильника «Гвардейские 3-и курганы», анализ погребального обряда и инвентаря позволяет отнести погребения 1, 2 и 7 к единому хронологическому горизонту и связать их с кочевым населением северокавказских степей раннесарматского времени.

Взаиморасположение могил может указывать на оставление их одной близкородственной группой: захоронения впускались в насыпь кургана в непосредственной близости, не нарушая друг друга (рис. 2,1). Погребения 1 и 2 имеют одинаковый уровень залегания. Погребение 7 демонстрирует иную конструкцию погребального сооружения, однако близкое расположение к погребениям 1 и 2 указывает на их связь. Данный участок кургана можно расценивать как комплекс близкородственных захоронений, родовых кладбищ, что характерно в первую очередь для кочевников раннесарматского времени волго-донских степей [Клепиков, 2002, с. 105], но встречается и в курганах Северо-Кавказского региона.

М.П. Абрамова, анализируя подкурганные погребения III-I вв. до н.э., отмечала наличие катакомб типа II и погребений в грунтовых ямах в погребальном обряде данного периода [Абрамова, 1993, с. 33-38]. Сочетание катакомб и погребений в грунтовых ямах в это время отмечает и Ю.А. Прокопенко [Прокопенко, 2014a, с. 111].

Вследствие того, что данные захоронения в кургане № 2 могильника «Гвардейские 3-и курганы» были впущены в насыпь более раннего времени, определить форму погребального сооружения удалось только для погребения 7 (рис. 3,8 ). М.Г. Мошкова и В.Ю. Малашев относят подобные конструкции к типу VI- ${ }_{3}$, для которого характерны округлой формы входные ямы, примыкающие к торцовой стенке камеры [Мошкова, Малашев, 1999, с. 174-176, c. 208, рис. 1]. По современному мнению В.Ю. Малашева, данная конструкция катакомбы является отклонением от стандарта катакомб типа $\mathrm{II}^{3}$. Для северокавказских степей 
аналогичные катакомбы получают распространение в III-І вв. до н.э. [Прокопенко, 2014б, рис. $51,1,21,52,1,9,52 \mathrm{~A}, 1]$. Характерной чертой катакомб данного типа является наклон дна могилы к дальней стенке [Прокопенко, 2014б, рис. 50,1, 51,21, 52A, 1, 53,1].

Вытянутое положение костяков, положение рук на груди или животе в погребениях сарматского времени кургана 2 могильника «Гвардейские 3-и курганы» и ориентировка погребенных в западный сектор с отклонениями - все это является распространенными признаками захоронений Северо-Кавказского региона этого периода [Абрамова, 1993, с. 35; Прокопенко, 2014a, с. 113].

Не противоречит кругу приведенных выше соответствий в обряде и инвентарь. Сероглиняный кружальный кувшин из погребения 7 (рис. 3,13) находит аналогии в предкавказских материалах III-I вв. до н.э. [Абрамова, 1993, рис. 8,8,19,21,24,25; Прокопенко, 2014б, рис. 51,9в, 167,22-24].

Глиняный кружальный сосуд из погребения 1 (рис. 2,3) также находит аналогии в погребениях оседлого и кочевого населения региона III-I вв. до н.э. [Абрамова, 1993, рис. 13,33; Прокопенко, 2014б, рис. 48,20, $170,34,45,46]$.

Погребение 2 можно считать синхронным погребениям 1 и 7. Расположенный в ногах погребенной сосуд (рис. 3,7 ) был фрагментирован и сохранился не полностью, из-за отсутствия верхней части сосуда невозможно определить его форму и дать прямые аналогии, но технологически он связывается с той же керамической традицией, что и рассмотренные выше сосуды. Рядом с сосудом у левой ноги находилась миска, в которой лежали кости барана и железный однолезвийный нож с горбатой спинкой. Миска (рис. 3,6), судя по технологии и составу теста, является продукцией местного северокавказского производ- ства. По оформлению вертикальной или слегка отогнутой наружу верхней части у загнутого внутрь бортика она сближается с группой мисок III-I вв. до н.э. [Абрамова, 1993, рис. 15,3,4,11,12,16; Прокопенко, 20146, рис. $159,13,160 \mathrm{~A}, 7]$.

Все рассмотренные сосуды являются продукцией мастерских оседлого населения предгорной полосы центральных и восточных районов Северного Кавказа, а также бассейна р. Кумы [Березин и др., 2012, с. 52].

Одна из особенностей погребального обряда погребений III-I вв. до н.э. - довольно широкое распространение обычая положения в могилу напутственной пищи; чаще всего фиксируются кости барана (ребра, лопатки и кости ног). Нередко кости барана находятся в миске, а среди костей животного - нож [Абрамова, 1993, с. 36; Прокопенко, 2014а, с. 115]. В.Ю. Малашев и В.Е. Маслов заметили, что обрядовая черта помещения костей животных в погребение в целом характерна для комплексов последних веков до н.э. ${ }^{4}$

Таким образом, исходя из анализа особенностей погребальных комплексов раннего железного века в кургане 2 могильника «Гвардейские 3-и курганы», можно говорить о том, что они оставлены кочевническим населением северокавказских степей III-I вв. до н.э.

\section{ПРИМЕЧАНИЯ}

${ }^{1}$ Исследование выполнено при финансовой поддержке РФФИ в рамках научного проекта № 2029-01020.

The reported study was funded by RFBR, project number 20-29-01020.

${ }^{2}$ Антропологические определения выполнены кандидатом исторических наук С.Ю. Фризеным.

${ }^{3}$ Благодарим В.Ю. Малашева за помощь в подготовке статьи.

${ }^{4}$ По сообщению В.Ю. Малашева и В.Е. Маслова. 
М.В. Кривошеев, В.И. Моисеев. Погребения раннесарматского времени с территории Чеченской Республики

\section{ПРИЛОЖЕНИЯ}

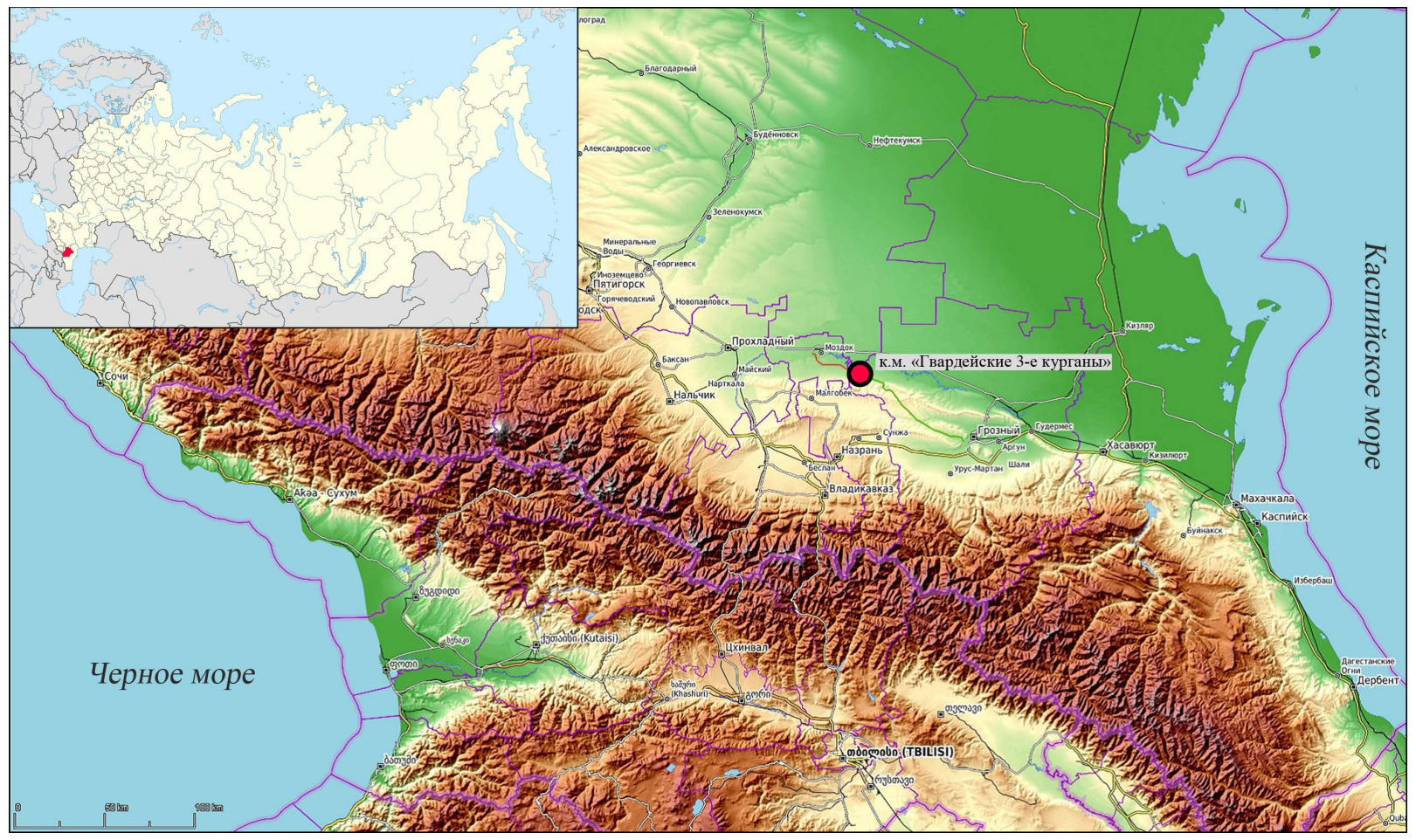

Рис. 1. Место расположения курганного могильника «Гвардейские 3-и курганы» Fig. 1. Location of the $3^{\text {rd }}$ Gvardeiskiy Kurgans (Gvardeyskiye 3 Kurgany) 


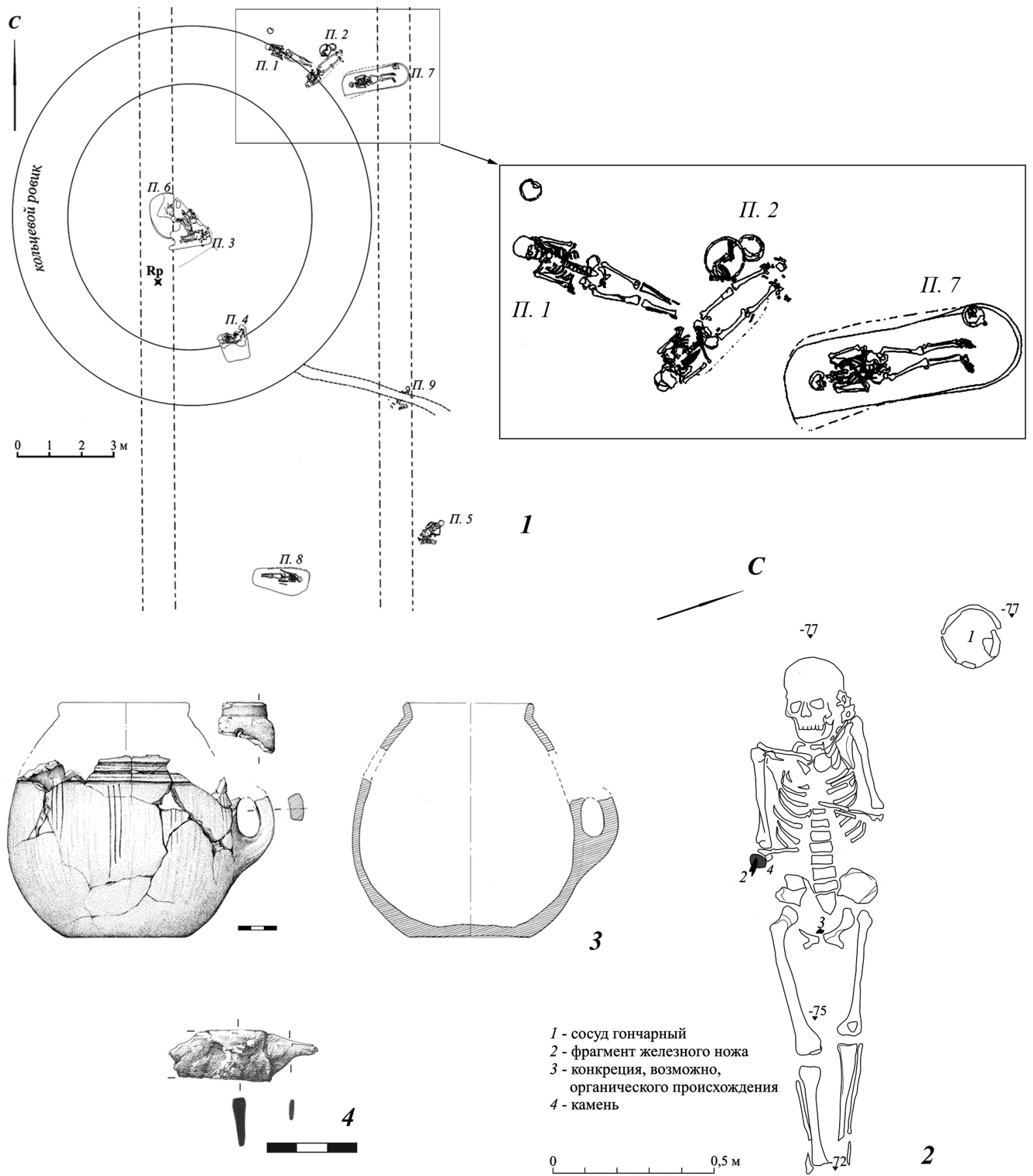

Рис. 2. Курганный могильник «Гвардейские 3-и курганы». Курган 2:

1 - план кургана; 2 - план погр. 1; вещи из погр. 1: 3 - сероглиняный сосуд; 4 - железный нож

Fig. 2. Gvardeyskiye 3 Kurgany. Kurgan 2:

1 - Kurgan layout; 2 - Burial 1 layout; Goods from burial 1: 3 - Gray-clay pottery; 4 - Iron knife 
М.В. Кривошеев, В.И. Моисеев. Погребения раннесарматского времени с территории Чеченской Республики
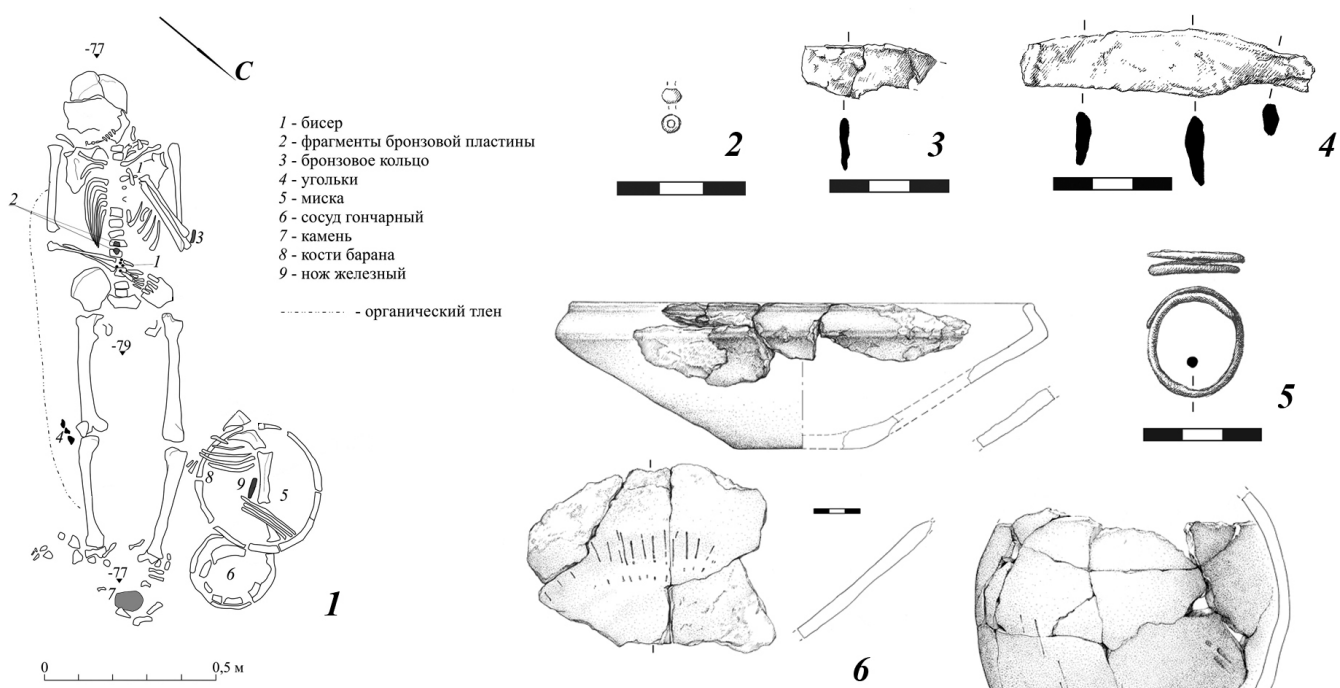

6
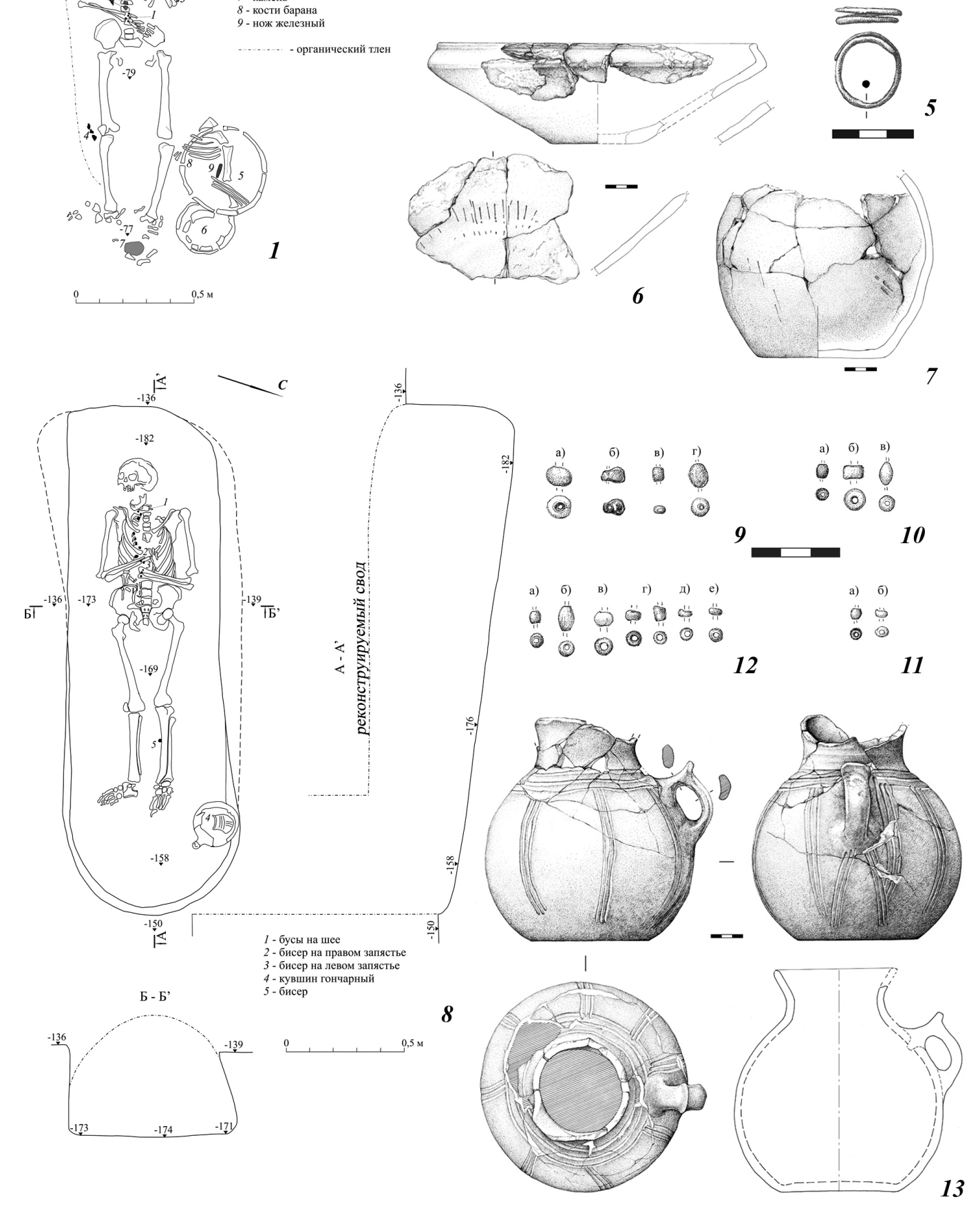

Рис. 3. Курганный могильник «Гвардейские 3-и курганы». Курган 2:

nогр. 2: 1 - план погр. 2; 2 - бисер; 3 - фрагмент бронзовой пластины; 4 - железный нож; 5 - бронзовое кольцо; 6 - сероглиняная миска; 7 - глиняный сосуд;

nогр. 7: 8 - план погр. 7; 9, 12 - бусы; 10-11- бисер; 13 - сероглиняный кувшин

Fig. 3. Gvardeyskiye 3 Kurgany. Kurgan 2:

burial 2: 1 - Kurgan layout; 2, 2 - beads; 3 - fragment of a bronze plate; 4 - iron knife; 5 - bronze ring;

6 - gray-clay bowl; 7 - earthen vessel;

burial 7: 8 - plan of burial 7; 9, 12 - beads; $10-11$ - beads; 13 - gray-clay jug 


\section{СПИСОК ЛИТЕРАТУРЫ}

Абрамова М. П., 1993. Центральное Предкавказье в сарматское время (III в. до н.э. - IV в. н.э.). М. : ИА PAH. $240 \mathrm{c}$.

Березин Я. Б., Каминский В. Н., Малашев В. Ю., 2012. Татарское городище и формирование памятников типа Татарка-Вербовка. М. : ТАУС. 206 с.

Клепиков В. М., 2002. Сарматы Нижнего Поволжья в IV-III вв. до н. э. Волгоград : Изд-во ВолГУ. 216 с.

Кривошеев М. В., Клещенко А. А., 2020. Новые материалы эпохи бронзы из раскопок в Чеченской Республике // Археологическое наследие Кавказа: актуальные проблемы изучения и сохранения. XXXI Крупновские чтения : материалы Междунар. науч. конф., посвящ. 50-летию Крупновских чтений и 50-летию Дербентской археологической экспедиции (Махачкала, 20-25 апреля 2020 г.). Махачкала : Изд. дом МавраевЪ. С. 119-121.

Мошкова М. Г., Малашев В. Ю., 1999. Хронология и типология сарматских катакомбных погребальных сооружений // Археология Волго-Уральского региона в эпоху раннего железного века и средневековья. Сер. «Научные школы Волгоградского государственного университета». Волгоград : Изд-во ВолГУ. C. $172-212$.

Прокопенко Ю. А., 2014а. Скифы, сарматы и племена кобанской культуры в Центральном Предкавказье во второй половине I тыс. до н.э. Часть 1. Ставрополь : Изд-во СКФУ. 446 с.

Прокопенко Ю. А., 2014б. Скифы, сарматы и племена кобанской культуры Центрального Предкавказья во второй половине I тыс. до н.э. Часть 2. Ставрополь : Изд-во СКФУ. 726 с.

\section{REFERENCES}

Abramova M.P., 1993. Tsentral'noye Predkavkaz'ye v sarmatskoye vremya (III v. do n.e. - IV v. n.e.) [Central Ciscaucasia in the Sarmatian time (the $3^{\text {rd }}$ century BC to the $4^{\text {th }}$ century AD)]. Moscow, Institute of Archaeology of the Russian Academy of Sciences. $240 \mathrm{p}$.

Berezin Ya.B., Kaminskiy V.N., Malashev V.Yu., 2012. Tatarskoye gorodishche i formirovaniye pamyatnikov tipa Tatarka-Verbovka [The fortified settlement of Tatarka and the formation of Tatarka-Verbovka type of sites]. Moscow, Taus Publ. 206 p.

Klepikov V.M., 2002. Sarmaty Nizhnego Povolzhya v IV-III vv. do n. e. [Sarmatians of the Lower Volga Region in the $4^{\text {th }}-3^{\text {rd }}$ centuries B.C.]. Volgograd, VolSU. 216 p.

Krivosheev M.V., Kleshchenko A.A., 2020. Novye materialy epohi bronzy iz raskopok v Chechenskoj Respublike [Bronze Age New materials from excavations in the Chechen Republic]. Arheologicheskoe nasledie Kavkaza: aktual'nye problemy izucheniya i sohraneniya. XXXI Krupnovskie chteniya: materialy Mezhdunarodnoy nauchnoy konferentsii, posvyashenoy 50-letiu "Krupnovskih chteiniy» i 50-letiu Derbentskoy archeologicheskoy ekspspeditsii (Mahackala, 20-25 aprelya $2020 \mathrm{~g}$.)[Archaeological heritage of the Caucasus: Topical Problems of Study and Preservation. The XXXI ${ }^{\mathrm{st}}$ Krupnov's Readings. Proceedings of the International Scientific Conference dedicated to the $50^{\text {th }}$ Anniversary of the Krupnov's Readings and the $50^{\text {th }}$ Anniversary of the Derbent Archaeological Expedition (Makhachkala, April 20-25, 2020)]. Makhachkala, Mavraev Publ., pp. 119-121.

Moshkova M.G., Malashev V.Yu., 1999. Hronologiya i tipologiya sarmatskih katakombnyh pogrebal'nyh sooruzhenij [Chronology and typology of the Sarmatian catacomb burial structures]. Arheologiya Volgo-Ural'skogo regiona v epohu rannego zheleznogo veka i srednevekov'ya. Ser. «Nauchnye shkoly Volgogradskogo gosudarstvennogo universiteta» [The Volga-Ural Region Archeology of the Early Iron Age and the Middle Ages]. Volgograd, VolSU, pp. 172-212.

Prokopenko Yu.A. 2014a. Skify, sarmaty i plemena kobanskoj kul'tury v Central'nom Predkavkaz'e vo vtoroj polovine I tys. do n.e. Chast' 1 [The Skythians, Sarmats and Koban Culture Tribes of the Central Caucasus (Predkavkaz'e) in the Second Half of the $1^{\text {st }}$ the Century B.C. Part 1]. Stavropol, NCFU. 446 p.

Prokopenko Yu.A. 2014b. Skify, sarmaty i plemena kobanskoj kul'tury v Central'nom Predkavkaz'e vo vtoroj polovine I tys. do n.e. Chast' 2 [The Skythians, Sarmats and Koban Culture Tribes of the Central Caucasus

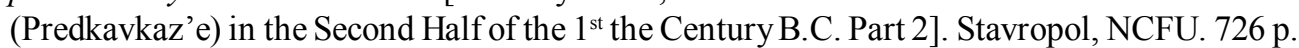


М.В. Кривошеев, В.И. Моисеев. Погребения раннесарматского времени с территории Чеченской Республики

\section{Information About the Authors}

Mikhail V. Krivosheev, Candidate of Sciences (History), Head of Laboratory of Archaeological Research, Volgograd State University, Prosp. Universitetsky, 100, 400062 Volgograd, Russian Federation, arhlab@volsu.ru, tyaf@mail.ru, https://orcid.org/0000-0003-4847-8209

Vladimir I. Moiseev, Researcher, Laboratory of Archaeological Research, Volgograd State University, Prosp. Universitetsky, 100, 400062 Volgograd, Russian Federation, v.moiseev@volsu.ru, https://orcid.org/0000-0002-5110-733X

\section{Информация об авторах}

Михаил Васильевич Кривошеев, кандидат исторических наук, заведующий лабораторией археологических исследований, Волгоградский государственный университет, просп. Университетский, 100, 400062 г. Волгоград, Российская Федерация, arhlab@volsu.ru, tyaf@mail.ru, https://orcid.org/0000-0003-4847-8209

Владимир Иванович Моисеев, научный сотрудник лаборатории археологических исследований, Волгоградский государственный университет, просп. Университетский, 100, 400062 г. Волгоград, Российская Федерация, v.moiseev@volsu.ru, https://orcid.org/0000-0002-5110-733X 